\title{
O Ensino de Língua Portuguesa na Cultura Lusófona: Reflexões Teóricas e Metodológicas
}

\author{
Neusa Maria Oliveira Barbosa BASTOS \\ (Universidade Presbiteriana Mackenzie / IP-PUC-SP) \\ Regina Helena Pires de BRITO \\ (Universidade Presbiteriana Mackenzie / IP-PUC-SP)
}

Resumo Parte de um estudo mais amplo a respeito das relações entre Língua, Cultura e Sociedade na formação de professores de Língua Portuguesa, vinculado ao IP-PUC/SP, este artigo reflete acerca de algumas propostas para a atualização de questões teóricas e metodológicas do ensino/aprendizagem. De maneira geral, as propostas existentes não se têm pautado numa metodologia centrada no aluno como sujeito de seu aprendizado, tendo o professor como auxiliador. A interação compromissada entre educador e educando não tem sido levada a cabo, havendo, no momento, uma inadequação teóricometodológica para realizações de ações profícuas para o processo de ensino/aprendizagem de Português.

Palavras-chave: ensino/aprendizagem; Língua Portuguesa; formação docente

\begin{abstract}
Being part of an extensive research about the connection involving Language, Culture and Society in the preparation of Portuguese Language teachers, developed at IP-PUC/SP, this article reflects on some proposals with the aim of updating questions related to theory and methodology on learning/teaching issues. In general, applications in progress have been concerned neither about a student centered methodology which points to the learner as the main subject of his/her learning, nor about the teacher as a tutor (auxiliary). Currently, the compromised interaction between educator and learner has not been implemented; to a certain extent there has been a theoreticalmethodological inadequacy of applying profitable actions for the Portuguese teaching-learning process.
\end{abstract}

Keywords: teaching / learning ; Portuguese Language; teachers' training proposal 
Como, de manhã, a pessoa abre o seu guarda-roupa para escolher a roupa adequada aos momentos sociais que ela vai enfrentar durante o dia, assim também, deve existir, na educação lingüística, um guarda-roupa lingüístico, em que o aluno saiba escolher as modalidades adequadas a falar com gíria, a falar popularmente, a saber entender um colega que veio do Norte ou que veio do Sul, com os seus falares locais, e que saiba também, nos momentos solenes, usar essa língua exemplar, que é o patrimônio da nossa cultura. (BECHARA, 2000)

Este trabalho situa-se na área de Língua Portuguesa: ensino/ aprendizagem e tem por tema uma reflexão sobre as propostas existentes para a atualização de questões teóricas e metodológicas.

As reflexões aqui apresentadas são parciais e resultam de um estudo mais amplo a respeito das relações entre Língua, Cultura e Sociedade na formação teórica e metodológica de professores de Língua Portuguesa, vinculado ao IP-PUC/SP (Instituto de Pesquisas Lingüísticas "Sedes Sapientiae" para Estudos de Português). O referido projeto objetiva promover, difundir e preservar a Língua Portuguesa em comunidades lusófonas na medida em que se preocupa com reformulações teóricas e metodológicas, com a produção de material didático e com a proficiência de professores/alunos de Língua Materna.

Tendo como pressuposto que o processo de comunicação em sala de aula apóia-se no conceito de que a educação, como fator de mudança social, inicia-se no reconhecimento do movimento dialético entre o social e a consciência humana, busca-se avaliar a atual situação para possíveis reformulações.

Com base nos estudos de análise do discurso de Maingueneau (1996) e nos estudos das representações sociais de Spinky (1993) e Goffman (1985), observa-se que, no quadro social da sala se aula, tem-se a noção da influência interpessoal estabelecida, com a intenção de, nessa prática social, desenvolver nos alunos habilidades específicas para a produção de textos orais e escritos.

Assim, conforme o estudo das representações sociais feito por Moscovici (1961 - in Spinky/1993), sabemos que o contexto é aspecto fundamental para delimitarmos as regras estruturadas pelo hábito e pelos conteúdos históricos que impregnam o imaginário social 
dos indivíduos. Deste modo, para estabelecer o papel do professor em situação de aula, deve-se procurar delimitar quais as regras que norteiam sua atuação e quais os conteúdos históricos que povoam professores e alunos no relacionamento de sala de aula.

Voltando o olhar para o surgimento da nação brasileira, temse uma forte influência da civilização européia em geral e da portuguesa em particular. Recortar-se-á a época em que Portugal se constitui como nação por volta do ano de 1100, momento em que os sacerdotes exerciam o magistério entre os próprios eclesiásticos e entre os nobres.

A situação não se modifica até a época do classicismo em Portugal, ocasião em que surgem as primeiras obras gramaticais que indicam a sistematização da língua portuguesa, o que vai propiciar o ensino da língua portuguesa paralelamente ao ensino da língua latina. Continua o magistério sendo uma prática dos indivíduos ligados ao clero, não sem que alguns nobres também participassem do processo ensino/aprendizagem.

Comum se fazia na sociedade da época a transmissão de conhecimentos através das aulas ministradas pelo clero e pela nobreza para o clero e para a nobreza. O mestre, pertencente ao clero ou à nobreza, era considerado um indivíduo de grande valor pelos conhecimentos que possuía e pela possibilidade de transmiti-los aos interessados, diferenciados na sociedade da época.

Assim, o papel importante no processo de transferência e transformação dos conhecimentos sempre foi desempenhado (entre outros) pelo professor que exerceu e exerce o papel, autorizado pela sociedade, de representante da ideologia vigente, isto é, a ideologia dos dominantes. Assim, cooptado ao aparelho ideológico do Estado, cumpre o seu papel sustentador da dominação pela língua.

Isto posto, passar-se-á a estudar o contexto de sala de aula, buscando as regras estruturadas pelo hábito e pelos conteúdos históricos desde a Idade Média até hoje.

Pela autoridade conseguida ao longo dos séculos, o quadro social que se estabelece na relação professor/aluno é de um relacionamento dominador/dominado, em que o cenário atua como um aliado do professor, pois a própria distribuição do espaço físico leva a um distanciamento entre mestres e educandos e pela severidade demonstrada até o início de nosso século, o resquício de tal postura ainda existe na atuação do professor em sala de aula. 
Por não concordar com isso, propõe-se uma conciliação entre essa postura e outra mais adequada aos dias atuais com base nos estudos de Goffman e Moscovici.

Não se prega aqui a derrocada da autoridade, sem a qual não se consegue conduzir com eficiência uma aula eficaz, em que ocorra um processo de ensino/aprendizagem envolvente a ponto de os alunos estarem atentos e motivados o suficiente para absorverem o conteúdo que está sendo ministrado. No entanto, deve-se diferenciar a autoridade do autoritarismo.

Este deve ser rejeitado por ser um ato arrogante, dominador, que não conduz a uma interação proveitosa dentro de sala de aula. $O$ ato de ensinar passa pelo já citado movimento dialético entre o social e a consciência humana, sendo o primeiro elemento - o social - que alimenta tal estado de coisas (a hierarquia professor/aluno - autoridade do professor/obediência do aluno contextualizada em sala de aula) e o segundo - consciência humana - que luta contra a vontade de quebrar a hierarquia, sabendo que não pode fazê-lo, pois estará infringindo uma lei social posta pelas suas formações ideológica (FI) e discursiva (FD), uma regra que norteia sua atuação imposta pela ideologia do dominante.

O social aponta para o direito ou poder de se fazer obedecer, de dar ordens, de tomar decisões, de agir, demonstrando influência, prestígio, crédito - o que deve ser conservado, para que se tenha clareza do papel do professor que é, sem dúvida, o indivíduo que, perante a comunidade, pode se fazer obedecer, sem ferir suscetibilidades, pois ele está investido do poder de dar ordens, tomar decisões e agir de acordo com o esperado. O social aponta, ainda, para o dever de obedecer, de acatar ordens, de agir, demonstrando respeito, compreensão, atenção, para que aprenda o que lhe está sendo ensinado.

A consciência humana revela-nos que é preciso seguir o binômio direito/dever para agir numa situação comunicativa bem sucedida. Assim, podemos afirmar que professor é aquele que reconhece publicamente o seu saber, procurando levá-lo a seus alunos.

Para que o professor desempenhe o papel acima, cumprindo o já mencionado conteúdo histórico que impregna o imaginário social de todos os indivíduos, é necessário que tenha a virtualidade que impulsiona a ação para querer: ser comunicador com o objetivo de atingir o interlocutor, interagir com o outro a fim de viver a 
subjetividade e a alteridade e para dever: ensinar, transmitindo o seu saber e formar, preparando o futuro cidadão.

É necessário, ainda, que possua a atualização que possibilita a concretização da ação, para poder exercer a profissão, tornar-se aceito pela comunidade para exercê-la, merecer o diploma para fazê-lo e para saber exercer o magistério por ter o conhecimento técnicocientífico-metodológico suficiente para isso e por gostar de "gente".

Por fim, é necessário que chegue à factividade, que é a realização da ação para fazer a ação de ensinar e para ser professor, sentindo-se integralmente professor. Então, poderá participar do processo de ensino/aprendizagem numa situação comunicativa interacional integrante e propiciadora de realização do ideal educacional.

Em todo esse processo, é preciso que o professor se recorde de que, cumprindo a ação integral apontada acima e cumprindo, ainda, os regulamentos da instituição de ensino à qual estiver vinculado, poderá exigir os seus direitos, como por exemplo: ter condições dignas de trabalho, ter estabelecido um plano de carreira, ter uma situação financeira estável compatível com a nobreza de sua tarefa e, principalmente, ter um diálogo sério e aberto com as mantenedoras das instituições de ensino para que se cumpram as convenções e acordos coletivos estabelecidos entre os sindicatos: patronal e da categoria de professores.

Em havendo conhecimento dos deveres e dos direitos, é preciso que se pense numa metodologia de ensino de Língua Portuguesa para que não continue havendo rejeição às aulas de língua materna, pois a questão metodológica não tem sido enfrentada pelos docentes de maneira eficaz: continua-se a ensinar Língua Portuguesa por meio do ensino da Gramática Tradicional, da metalinguagem, da gramática pela gramática, da gramática como um fim em si mesma.

A noção de que a língua é um conjunto de usos diversos tem sido difundida entre os professores do ensino fundamental e médio que, ao terem contacto com tal postura, acatam-na, sem, no entanto, saberem como proceder com relação ao ensino de língua materna, incluindo nele essas diversidades.

A partir desse caos, os professores ou permanecem rigidamente ligados ao ensino de Língua Portuguesa, através da Gramática Tradicional, exigindo do aluno um saber gramatical profundo, ou desligam-se da descrição e normativização da língua. 
Passam, assim, a atribuir aos alunos uma liberdade total de escolha de construções de orações, períodos, parágrafos, textos, desconsiderando a ausência de conhecimento, seus repertórios, que, sem consciência das variações existentes, mostram-se incapazes de "escolher". Continua esse educando, portanto, com o uso lingüístico de sua comunidade, tanto na fala quanto na escrita, sem a possibilidade de organizar um texto de diversas maneiras, adequando-o à situação do momento da produção. Neste ponto vale pensar numa educação lingüística, aquela que possibilita ao educando conhecer/aprender diversas modalidades lingüísticas, reconhecendo-lhes a pertinência e a adequação de uso e procurando torná-lo um indivíduo competente lingüisticamente nas situações reais de interação social que experimenta. Repetindo a célebre afirmação de Bechara,

A grande missão do professor de língua materna [...] é transformar seu aluno num poliglota dentro da sua própria língua, possibilitandolhe escolher a língua funcional adequada a cada momento de criação e até, no texto em que isso se exigir ou for possível, entremear várias línguas funcionais ${ }^{1}[\ldots]$. (BECHARA, 2007, p. 14)

Sendo assim, não tomaremos como pressuposto a noção de "certo e errado", imposta pelas normas gramaticais, nem mesmo a noção de "liberdade" lingüística, levada a cabo por radicalizações das posturas atuais. Por princípio, com base na sociolingüística, teremos o objetivo de revelar ao aluno que, na língua, há várias possibilidades de manifestação e ensinar-lhe as variedades pertinentes a cada momento.

Focalizaremos, como exemplificação, o ensino do emprego dos pronomes pessoais, delimitado unicamente ao uso do pronome pessoal oblíquo tônico mim em confronto com o pronome pessoal reto eu. Tomando como pressuposto, a noção de "certo e errado", imposta pelas normas gramaticais, consideramos que o pronome mim tem ocorrido de maneira incorreta, não só na fala dos adolescentes, mas também na sua escrita.

Mudando do enfoque gramatical para o lingüístico, consideramos as mesmas realizações do pronome mim, não incorretas,

${ }^{1}$ O lingüista Eugenio Coseriu (1979: 50) define uma língua funcional como um "sistema de oposições funcionais e realizações normais". 
mas pertencentes ao uso popular, terminologia adotada por Pinto (1986), que entendemos como um uso "descontraído" da língua, nas variedades diatópicas (diferentes localidades) e diastráticas (diferentes profissões, diversas camadas sociais e variadas faixas etárias).

Em adotando uma postura lingüística, não condenamos o uso popular que propicia aos usuários uma comunicação eficaz. No entanto, julgamos necessário que se mostre que, além da modalidade lingüística por eles utilizada, há uma variedade culta que poderá lhes servir num momento mais formal, em que precise, por exemplo, tratar alguém hierarquicamente superior a eles, ou, ainda num momento de produção escrita em que se espera uma elaboração mais cuidada da língua. Acreditamos na necessidade de os alunos do ensino fundamental, principalmente os das séries terminais, incorporarem, em sua linguagem, o uso culto. Julgamos importante o ensino "correto" do pronome mim, uma vez que, muitas vezes, tais alunos se submetem aos "vestibulinhos" existentes para o ingresso no ensino médio, em que lhes são cobradas as normas gramaticais.

De nossa experiência com o ensino fundamental e com o ensino médio, no contacto com jovens na faixa etária de 13 a 15 anos, de nível sócio-econômico elevado, pudemos detectar as ocorrências desse pronome em conversações informais e em textos escritos produzidos em sala de aula pelos mesmos jovens.

$\mathrm{Na}$ modalidade oral, a maioria dos alunos utilizava construções como as que se seguem:

(1) Ganhei uma grana pra mim comprar um disco.

\section{(2) Há muita diferença entre eu e você.}

Observamos a já conhecida troca do pronome reto eu pelo pronome oblíquo mim, em construções como (1), e a substituição do pronome oblíquo mim pelo pronome reto eu, em construções como (2), o que confirma o desconhecimento da norma para o uso dos pronomes citados.

Essa constatação indica que o domínio do aluno sobre esse mecanismo fica no nível popular, pois somente uma minoria faz uso da construção de acordo com a norma culta: 


\section{(3) Vai ser barra para eu contar essa nota pro meu pai!}

Tais alunos usam essa construção não por a terem aprendido na escola, mas, provavelmente, por a terem adquirido em suas relações familiares, pois são provenientes de ambientes em cujo domínio lingüístico, muito possivelmente, se inclui tal realização.

$\mathrm{Na}$ modalidade escrita, o uso não se altera. Os mesmos alunos, na produção de um texto dissertativo sobre violência, escreveram:

(4) Na minha opinião, não há como combater a violência, a não ser com a pena de morte, pois se alguma coisa acontecesse com meu pai, por exemplo: um seqüestro, para mim fazer justiça, eu mesmo ia matar esse seqüestrador se pudesse...

(5) A violência está acontecendo a toda hora em nossa cidade. Há vários tipos de violência: 0 assalto a mão armada, o estupro, a agressão por palavras, etc...

Para eu começar a discorrer sobre a violência, vou me fixar naquela que acho mais revoltante: o estupro.

Confirmamos, assim, que não se segue a norma gramatical também no texto escrito (4), a não ser pela mesma minoria (5) que a utiliza "corretamente" em sua conversação, transcodificando-a para sua produção escrita.

Se buscarmos, neste momento, dados sobre o assunto em Bechara (1992, p. 95 e 310) e em (Bechara, 1999, p. 164 e 566), encontraremos:

As formas $e u, t u$, ele, ela, nós, vós, eles, elas, que funcionam como sujeito, se dizem retas. A cada um destes pronomes retos, corresponde um pronome obliquo que funciona como complemento e pode apresentar-se em forma átona ou tônica. Ao contrário das formas átonas, as tônicas vêm sempre presas a preposição.

As virtudes se harmonizam, os vícios discordam entre si. (Marquês de Maricá)

Isto épara eu faz̧er - Se a preposição seguida de pronome não serve de introduzir este pronome (que funciona como sujeito), mas um infinitivo, usam-se as formas retas $e u$ e $t u$, e não mim e ti: Isto é para mim (a preposição introduz o pronome) 
Isto é para en fazer (a preposição introduz o infinitivo: isto é para que eu faça).

Estas explanações foram encontradas, respectivamente, nos capítulos referentes à Morfologia (Pronome) e à Sintaxe (Regência), entretanto não esclarecem o problema aqui enfocado, uma vez que o abordam mencionando a língua exemplar que insiste na lição do rigor gramatical, sem levar em conta a tendência popular que já ocorria na década de 70 , de trocar os pronomes mim por eu e vice-versa.

Sabendo-se que a gramática não deve ser utilizada como um fim em si mesma, mas como um meio, o que já observamos no início do presente texto, entendemos que o aluno não deve decorá-la, mas deve saber manuseá-la, e que o professor deve saber como torná-la acessível aos alunos, não se atendo somente à classificação das palavras e à análise de orações, mas buscando soluções para esclarecer diversidades de uso.

Deste modo, para que o mestre cumpra o seu papel sóciopolítico de integração do aluno à sociedade com a possibilidade de uso da língua de acordo com o uso do dominante, propomos que esses casos mais comuns de uso da língua passem a merecer um tratamento mais criterioso por parte dos professores que estarão, assim atuando, ampliando as possibilidades de o aluno conhecer as diversas maneiras de se expressar, podendo optar por esta ou aquela de acordo com a situação em que esteja inserido e com o contexto de sua produção.

Explicitaremos algumas das atividades que julgamos devam ser desenvolvidas com os alunos para que entendam o porquê de estudar a norma culta:

$1^{\mathrm{o}}$ - esclarecimento sobre as variedades lingüísticas existentes em nosso instrumento de comunicação e expressão: a Língua Portuguesa, enfatizando a riqueza e o patrimônio que isso representa, destacando o contexto lusófono;

$2^{\circ}$ - explanação sobre a validade de todas essas variedades, que se apresentarão de uma ou outra forma, adequando-se o uso às diversas situações de comunicação;

$3^{\circ}$ - diferenciação entre a modalidade falada e a modalidade escrita, apontando aquela como mais usada, por ter sido adquirida desde a infância no convívio familiar, e esta como 
a mais elaborada, por ter sido adquirida, a partir da idade escolar, não de forma descontraída, mas, por meio da sistematização imposta pela escola, aparelho ideológico;

$4^{\circ}$ - leitura de textos de diferentes tipologias, reveladores das variedades lingüísticas apresentadas anteriormente;

$5^{\circ}$ - elaboração de exercícios dos pronomes mim/eu, formulados pelos próprios alunos.

Tais procedimentos têm se mostrado eficazes na nossa prática, pois o aluno, primeiramente, se sente seguro ao saber que a língua utilizada por ele em sua variedade popular é, também, "correta", e que, dessa forma, ele poderá continuar sua conversação descontraída e, por vezes, manifestá-la por meio da escrita. Em segundo lugar, adquire uma outra variedade, a culta, que passa a empregar em situações mais formais de conversação e em aulas de redação, momento em que produz textos escritos podendo estar mais atento ao produto final, revendo-o e reescrevendo-o, se necessário.

Finalmente, julgamos relevante conscientizar os professores das escolas de ensino fundamental e médio de que o apego às classificações morfológicas e às análises sintáticas leva os alunos, unicamente, a se revoltarem contra o ensino de língua materna (que consideram enfadonho e repetitivo), pois eles não vêem utilidade naquilo que estão aprendendo. Conscientizá-los, ainda, de que a aceitação da variedade dos alunos como única e verdadeira leva-os ao não crescimento lingüístico, pois nada de inovador será passado a ele. E, por fim, conscientizá-los de que a noção de variedade lingüística abrirá várias possibilidades de escolha para que o aluno opte, entre elas, pela mais adequada à situação de uso. Agindo assim, o professor estará efetivamente contribuindo para que os seus alunos saibam se comunicar melhor e consigam superar, com mais facilidade, as barreiras sociais que lhes serão impostas.

Conclui-se que, de maneira geral, as propostas existentes não se têm pautado numa metodologia centrada no aluno como sujeito de seu aprendizado, tendo o professor como auxiliador de tal processo. Assim, a interação compromissada entre educador e educando não tem sido levada a cabo, havendo no momento, portanto, uma inadequação de metodologias e teorias para realizações de ações profícuas para o processo de ensino/aprendizagem de Português. 


\section{Referências Bibliográficas}

BASTOS, N. M. O. B. O papel do professor no ensino de Lingua Portuguesa. São Paulo: Selinunte, 1995.

BECHARA, E. Ensino da gramática. Opressão? Liberdade? 12. ed. São Paulo: Ática, 2007.

A norma culta face à democratização do ensino. 2000. Disponível em : < http://www.academia.org.br/abl/cgi/cgilua.exe/ sys $/$ start.htm?infoid $=4284 \&$ sid $=531>$. Acesso em: 24 mar. 2008 .

1999.

Moderna gramática portuguesa. Rio de Janeiro: Lucerna, . Moderna gramática portuguesa. São Paulo: Nacional, 1992.

COSERIU, E. Sincronia, diacronia e história. Rio de Janeiro: Presença; São Paulo:USP, 1979.

GOFFMAN, E. A representação do eu na vida cotidiana. 5. ed. Trad. Maria Célia Santos Raposo. Petrópolis: Vozes, 1985.

MAINGUENEAU, D. Pragmática para o discurso literário. São Paulo: Martins Fontes, 1996.

PINTO, E. P. A lingua escrita no Brasil. São Paulo: Ática, 1986. (Série Fundamentos, n. 17)

SPINKY, M. J. (Org.) O conhecimento no cotidiano: as representações sociais na perspectiva da psicologia social. São Paulo: Brasiliense, 1993. 